\title{
Peer Support for People Living With HIV: A Scoping Review
}

Anita Øgård-Repål, MSc, BSN ${ }^{1}$ iD

Rigmor C. Berg, $\mathrm{PhD}, \mathrm{BSc}^{2,3}$

Mariann Fossum, $\mathrm{PhD}, \mathrm{BSN}^{1}$ iD

Peer support for people living with HIV has gained increasing traction and is considered a way to take an active role in self-management. The existing research examining peer support interventions has reported promising evidence of the benefits of peer support. The purpose of our scoping review was to describe research on peer support for people living with HIV. We included 53 studies and sorted them into analytic categories and conducted descriptive analyses. The studies that were published between November/December 2000 and May 2021, had a range of study designs and heterogeneous priority groups, and included 20,657 participants from 16 countries. We identified 43 evaluations of the effect of peer support and 10 evaluations of implementation, process, feasibility, cost of peer support. We also categorized peer support by key functions, finding that the most common key functions were linkage to clinical care and community resources and assistance in daily management, with only one study directly related to chronic care. There is growing research interest in peer support for people living with HIV, particularly in high-income countries and related to the evaluation of effects. The revealed gaps of prioritized functions of peer support have implications for further research. Further focus on interventions addressing secondary prevention related to noncommunicable diseases as part of a care package is recommended to meet people's needs and preferences and increase selfmanagement related to a chronic lifelong condition.

Keywords: people living with HIV; chronic disease; peer support; medication adherence; antiretroviral therapy

Health Promotion Practice

Month XXXX Vol. XX, No. (X) 1-19

DOI: $10.1177 / 15248399211049824$

Article reuse guidelines: sagepub.com/journals-permissions (c) (1)

(C) 2021 The Author(s)
A t the end of 2020, there were an estimated 37.6 million people living with human immunodeficiency virus (PLHIV) worldwide, with approximately 25.4 million undergoing antiretroviral therapy (ART; World Health Organization [WHO], 2021). Although global and national actions have halted and reversed the acquired immunodeficiency syndrome (AIDS) epidemic and reduced HIV incidence overall, HIV infections are on the rise in some countries and regions (WHO, 2021). Furthermore, ART provisions in highly endemic settings, such as sub-Saharan Africa, are challenged due to shortages linked to universal health coverage (UNAIDS, 2020). Thus, HIV remains a public health concern worldwide. The Global Health Sector Strategy on HIV, 2016-2021 (WHO, 2016b), outlines fasttrack actions to be implemented as an HIV response to the 2030 Agenda for Sustainable Development (United Nations). These actions must address challenges related to different health care systems and varying health care coverage (such as inconsistent price of medications) across countries. A multisectoral response is outlined as a strategy highlighting the importance of involving the community, particularly PLHIV, for effective delivery of health services (WHO, 2016b).

People from key populations, that is, those at elevated risk of acquiring HIV infection (including sex workers,

\footnotetext{
${ }^{1}$ University of Agder, Grimstad, Aust-Agder, Norway

${ }^{2}$ Norwegian Institute of Public Health, Oslo, Norway

${ }^{3}$ University of Tromsø, Tromsø, Norway
}

Author's Note: We would like to thank librarian Ellen Sejersted for her excellent support and recommendations during the search process, and Editage (www.editage.com) for English language editing. The PhD-project is supported by Dam Foundation. Address correspondence to Anita Øgård-Repål, Centre for Caring ResearchSouthern Norway, Department of Health and Nursing Science, University of Agder, Grimstad, Østerveien 18, Kristiansand, 4631, Norway; email: anita.ogard-repal@uia.no. 
people who inject drugs, prisoners, transgender people, and men who have sex with men) tend to have less access to ART and health care services (Liamputtong, 2007; Sokol \& Fisher, 2016). However, for PLHIV and receiving ART, HIV has become a chronic lifelong condition (CLLC; WHO, 2021). An increasing burden for PLHIV is coinfections such as hepatitis, tuberculosis, and other comorbidities (WHO, 2016b), the most prevalent being noncommunicable diseases and mental health disorders (Brandt, 2009; Parcesepe et al., 2018; WHO, 2016b).

Although the life expectancy for PLHIV has increased dramatically, they continue to face other challenges, such as discrimination, stigma, and self-stigma (Grønningsæter \& Hansen, 2018; Pantelic et al., 2019; WHO, 2016b). Since the beginning of the epidemic, HIV infection has been associated with social stigma and prejudice, and it remains one of the most stigmatized diseases in almost every culture, worldwide (Pantelic et al., 2019; Relf et al., 2021). Furthermore, apart from utilizing health care services for HIV medical care, many PLHIV disconnect from society owing to stigma and discrimination (Berg \& Ross, 2014; Chaudoir \& Fisher, 2018; Relf et al., 2021). The societal prejudice can harm those living with the virus in numerous ways, perhaps most detrimentally, through mental health issues (Chaudoir \& Fisher, 2018; Relf et al., 2021).

The range of health challenges indicates the importance of continued strengthening of self-management and involvement of PLHIV in their own health care services. This may contribute to empowerment and a more tailored health care service (Venter et al., 2017). Peer support from the larger HIV community can be important in this regard (Positively UK, 2016) and has been found to reduce stigma (Dunbar et al., 2020). Dennis (2003) defined the concept of peer support as "the giving of assistance and encouragement by an individual considered equal"' (p. 323).

Peer support for PLHIV grew out of the 1980s activists' reaction to combat stigma and discrimination, advocating for better treatment and care. Peer support still forms communities for people experiencing stigma or fear of exposure and ostracization (Positively UK, 2016). After the introduction of ART, peer support has become a tailored, person-centered method to provide linkage and adherence to HIV medical care, as well as support for PLHIV in taking an active role in self-management of their CLLC (Fisher, 2014; WHO, 2016a). Thus, the provision of peer support is one way of involving patients to strengthen supportive resources in health care services and increase self-management (Fisher, 2014). There is increased recognition that peer support complements general health care services and contributes to meeting consumers' health care needs (Fisher,
2014; Fisher et al., 2018; WHO, 2016a). The Peers for Progress program draws out four key functions of peer support: (1) assistance in daily management, (2) social and emotional support, (3) linkage to clinical care and community resources, and (4) ongoing support related to chronic disease, that is, flexible, accessible support available to patients when the need arises (Fisher, 2014; Fisher et al., 2018).

A systematic review of peer support among "hardly reached individuals," indicates that peer support may be an effective and preferred way to reach people who do not use ordinary health care services (Sokol \& Fisher, 2016). Conversely, a systematic review of nine studies on peer interventions, reported the varying effect of peer support (Genberg et al., 2016). The findings of Genberg et al. (2016) are supported in a recent review on effects of peer-led self-management interventions on ART adherence and patient-reported outcomes, which showed unclear but promising effects (Boucher et al., 2020). Additionally, findings indicate that peer support is flexible enough to be applied to people with different health problems in various settings (Genberg et al., 2016; Simoni et al., 2011; Sokol \& Fisher, 2016) and has positive effects, especially in lower middle- and low-income countries (Dave et al., 2019).

Given that existing research examining peer support interventions in several health service areas and among different groups has reported inconsistent evidence of the benefits of peer support (Genberg et al., 2016), there is a need for further research. To date, no review has consolidated existing research or described the scope of the empirical work undertaken on peer support for PLHIV. Therefore, this scoping review aims to document the current status of empirical research on peer support for PLHIV, to describe the characteristics of previous studies through a brief overview, and to summarize key findings from each study category to identify knowledge gaps and offer suggestions for further research.

\section{METHOD}

\section{Design}

To identify the range of available evidence on the topic, a scoping review was conducted following methodological framework of scoping reviews (Arksey \& O’Malley, 2005; Levac et al., 2010; Peters et al., 2017) and is in accordance with the PRISMA (Preferred Reporting Items for Systematic Reviews and MetaAnalyses) extension for scoping reviews (Tricco et al., 2018). Unlike a systematic review on effects of intervention, diagnostic test accuracy or another narrow question, a scoping review has a broader scope, examining the extent, range, and nature of research activity on a 
specific topic (Peters et al., 2020). The methods, objectives, and inclusion criteria of this scoping review, were specified in advance and documented in a published protocol (CRISTIN ID = 635403).

\section{Search Strategy for Identification of Studies}

Our preliminary searches in the JBI (Joanna Briggs Institute) Database of Systematic Reviews and Implementation Reports and PROSPERO identified relevant reviews and key words. We used population, concept, and context as our search framework because the aim of the scoping reviews implies that the context is not predefined (Booth et al., 2016). Articles published between 1981 and 2021 were searched on eight electronic databases-MEDLINE (OVID), MEDLINE In-Process (OVID), Embase (OVID), CINAHL (EBSCOhost), PsycINFO (OVID), SocINDEX (EBSCOhost), Social Work Abstracts (EBSCOhost), and BASE (Bielefeld Academic Search Engine). Articles published after 1981 were included, as this was the first year when studies on HIV/AIDS were published. The search was conducted in May 2021. Our search strategy incorporated prespecified subject headings and text words in the titles and abstracts, adapted for each database. One of the reviewers (AØR) conducted the search together with an information search specialist/librarian, who was also consulted regarding the search strategy. The search strategy is shown in the Supplemental Material. In collaboration with the information search specialist/librarian, we supplemented the database searches with searches in Google Scholar, the U.K. government website, and CORE (a website that aggregates all open access research outputs from repositories and journals worldwide and makes them available to the public). Additionally, we performed hand searches in the reference lists of the included studies and relevant reviews and forward citation searches through the Web of Science (conducted June 2021).

\section{Eligibility Criteria}

Considering the aim of the review, the main inclusion criterion was that a study used empirical quantitative and/or qualitative research methods to address the topic of peer support among PLHIV. Moreover, both, those receiving and those providing peer support needed to be PLHIV aged 18 years and older. We followed the definition of peer support interventions/programs proposed by Dennis (2003), whereby the provision of assistance and encouragement is from an individual considered equal. Specifically, PLHIV had to use their own experiences to support other PLHIV, through face-to-face interaction.
Furthermore, we considered studies ineligible if they included children and youth, focused on primary prevention of HIV or mother-to-child transmission, or described PLHIV support groups. However, when populations or interventions were mixed (e.g., included both adults and youth), a study was included if at least half of the population or intervention met the inclusion criteria or if the results were reported separately for our population and intervention of interest. We enforced no limits regarding settings or publication format but included only publications in English or Scandinavian languages (Norwegian, Swedish, Danish).

\section{Selection of Literature}

We stored retrieved references in an Endnote database, X9 (Thomas Reuters, New York, NY), deleted duplicate entries, and imported references to the web-based software platform, Rayyan (Ouzzani et al., 2016). Using Rayyan, two blinded reviewers independently screened all titles and abstracts according to the inclusion/exclusion criteria. We promoted all relevant publications to full-text, and the two blinded reviewers independently screened the full texts. They attempted to retrieve full texts of any studies that were not available in the public domain, by contacting the main author. Throughout the screening process, we resolved differences in opinions through reexamination of the studies and subsequent discussion. If necessary, a third reviewer decided.

\section{Data Extraction and Synthesis (Charting Data)}

Methodological quality assessment is not a prerequisite for scoping reviews. Therefore, we did not appraise the included studies (Peters et al., 2020). One reviewer (AØR) performed data extraction. Two other reviewers checked for completeness and accuracy of the extracted data. A predesigned and piloted data extraction form was used to ensure standardization and consistency (Peters et al., 2020). We extracted data regarding author, year, study characteristics (e.g., country, study design, sample size), population characteristics (e.g., gender, sexual identity), peer support characteristics (e.g., term for peer support, duration, content, and settings), and main findings/results. We also categorized the interventions based on four key functions of peer support described by Fisher et al. and the Peers for Progress program (Fisher, 2014). Studies with unclear or minimally described intervention characteristics were excluded. We key worded (Clapton et al., 2009) each study using these variables and compiled the data in a single spreadsheet. We grouped them according to their main characteristics and conducted descriptive analyses 
using frequencies and cross-tabulations. The grouping included sorting the studies into clusters based on how they were observed to be related to each other (Arksey \& O'Malley, 2005; Clapton et al., 2009). Similarly, we copied the main findings of the qualitative studies relevant to peer support, in a Microsoft Word document. The findings are summarized in the data set.

\section{RESULTS}

The searches resulted in 6922 individual records, of which 230 were considered potentially relevant (Figure 1). Eighty-seven studies met the inclusion criteria. The high number of included studies and the volume of data made it necessary to separate the results from the two reports. This review addresses all studies that examined the effects of peer support and evaluated implementation, process, feasibility, and cost.

Thus, in this study, we included 53 studies (Table 1).

\section{Characteristics of the Included Studies}

The main characteristics of the 53 included studies are presented in Tables 1 and 2. For ease of reporting, each study was given a number. All studies were published in English. The number of publications on the topic of peer support for PLHIV has grown rapidlyfrom no publications prior to 2000 to only a few publications between 2000 and $2009(n=9)$ to 44 publications between 2010 and 2021. The study designs varied, but most were RCTs $(n=18)$ or mixed-method studies $(n=$ 12). The study settings varied, but most studies took place in the United States $(n=24)$, while the fewest studies took place in Europe $(n=2)$. The total number of participants in the included studies was 20,657, with most of the studies including both males and females $(n=37)$, but five studies prioritized only males and six prioritized only females. Only four studies included nonbinary gender as the priority population. However, nine studies reported nonbinary gender among participants.

\section{The Key Functions of Peer Support}

Our analysis demonstrates the different roles and key functions (Fisher, 2014) of peer support delivered, in the included studies. The most common key functions of the interventions were linkage to clinical care and community resources $(n=41$, Studies $1-4,7-13,15-20,22-23$, $26-28,30-35,37-45,48-50,53)$, followed by assistance in daily management $(n=32$, Studies $5-6,9-13,18-$ $23,27-28,35-40,42-44,46-48,50-53)$ and social and emotional support ( $n=28$, studies 1-9, 11, 15, 19-20, $22-23,27-28,33,35,37-44,50)$. Several peer support interventions have a combination of the described functions. Notably, only one study (44) explicitly focused on ongoing support related to chronic disease. In two studies, the intervention could not be categorized by key functions.

\section{Terms and Labels}

We identified 13 different labels/names for peer supporters. Between 2000 and 2009, the terms "peer," "peer counselor/advocate/supporter/mentor/health worker," and "health advocate" were used. Between 2010 and 2021 , in addition to the prior labels, a range of new labels appeared: "peer educator/navigator/worker/facilitator/ case manager/caregiver/adherence supporter/interventionist," "community health worker," "support worker," and "community care coordinator." All terms represent PLHIV serving as peers. The most frequently used labels across all included studies were "peer" $(n=10)$, "peer counselor" $(n=7)$, and "peer navigator" $(n=6)$.

\section{Categories of Studies}

We categorized studies by objective/aim (see Figure 1). When a study fit into more than one category, we placed it in the category that most closely matched the overall objective of the article. This review included two study categories: studies evaluating effects of peer support interventions $(n=43)$ and studies evaluating their implementation, process, feasibility, and cost $(n=10)$. We note that six larger projects on peer support had two or more related publications that examined the intervention: all six projects had at least one publication on the effects of peer support; four projects conducted a process evaluation, and two projects included a program description.

Studies About Effectiveness of Peer Support. Of the 43 studies with a main focus on the effectiveness of a peer support intervention (Studies 3-7, 9-13, 15-23, 25-27, 29, 31-38, 41-49, 51-53), most were published within the past 10 years $(81 \%)$, were set in the United States (44\%) and Uganda (12\%), and were RCTs (42\%) and used mixed methods (19\%; Table 3). Only two studies were conducted in Europe (Netherlands and Spain: Studies 4 and 45). In total, 18,833 participants were included in the experimental studies at baseline. Of the 30 effectiveness studies that had a comparison group, 21 of these groups received ordinary health care services.

Although, the priority population of the effectiveness studies was diverse, the studies mainly included female and male participants living in settings associated with 


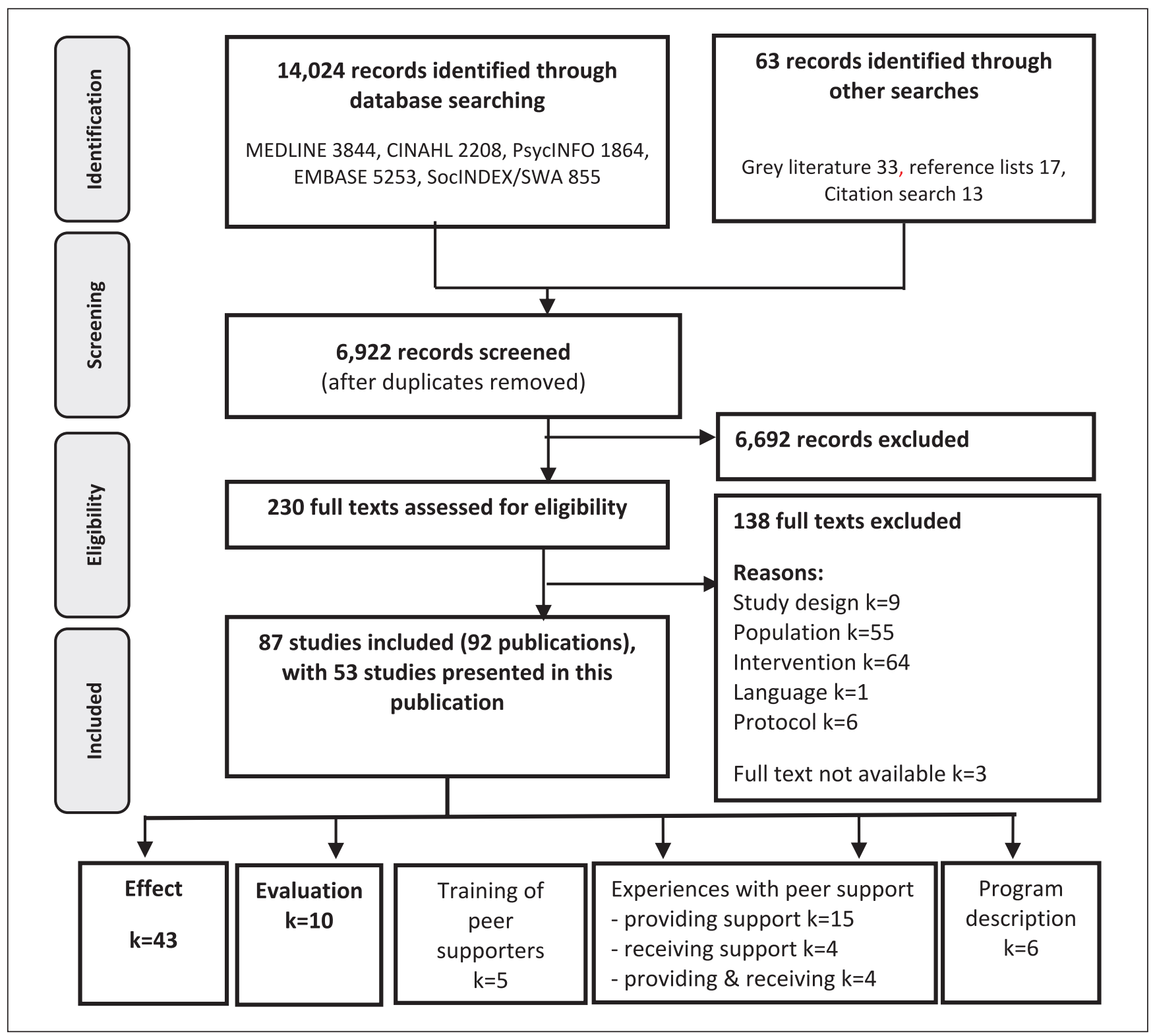

FIGURE 1 PRISMA (Preferred Reporting Items for Systematic Reviews and Meta-Analyses) Flow Diagram of Literature Reviewing Process

social factors that created barriers to accessing effective and affordable HIV health care services. Five studies included only women (Studies 5, 20, 25, 34, 51), four included people who inject drugs (Studies 5, 7, 20, 43), four recruited men who have sex with men (Studies 27, $36,38,46$ ), and two U.S. studies specifically recruited people of color (Studies 9, 29).

About the chosen theoretical framework, the interventions differed. Most interventions were based on diverse frameworks, such as social cognitive theory (Studies 17,
19, 23, 29), several social support frameworks (Studies 9, $7,42,43)$, stress, and coping models (Study 5). Several interventions were based on the information, motivation, and behavioral skills model ( $n=7$; Studies 15, 21, 26, 27, 36, 41, 46). Eighteen studies did not report a theoretical framework.

ART initiation and/or adherence (19 studies), viral load (16 studies), and cluster of differentiation 4 counts (CD4; 8 studies) were the most frequently measured outcomes in the included studies related to effectiveness. 


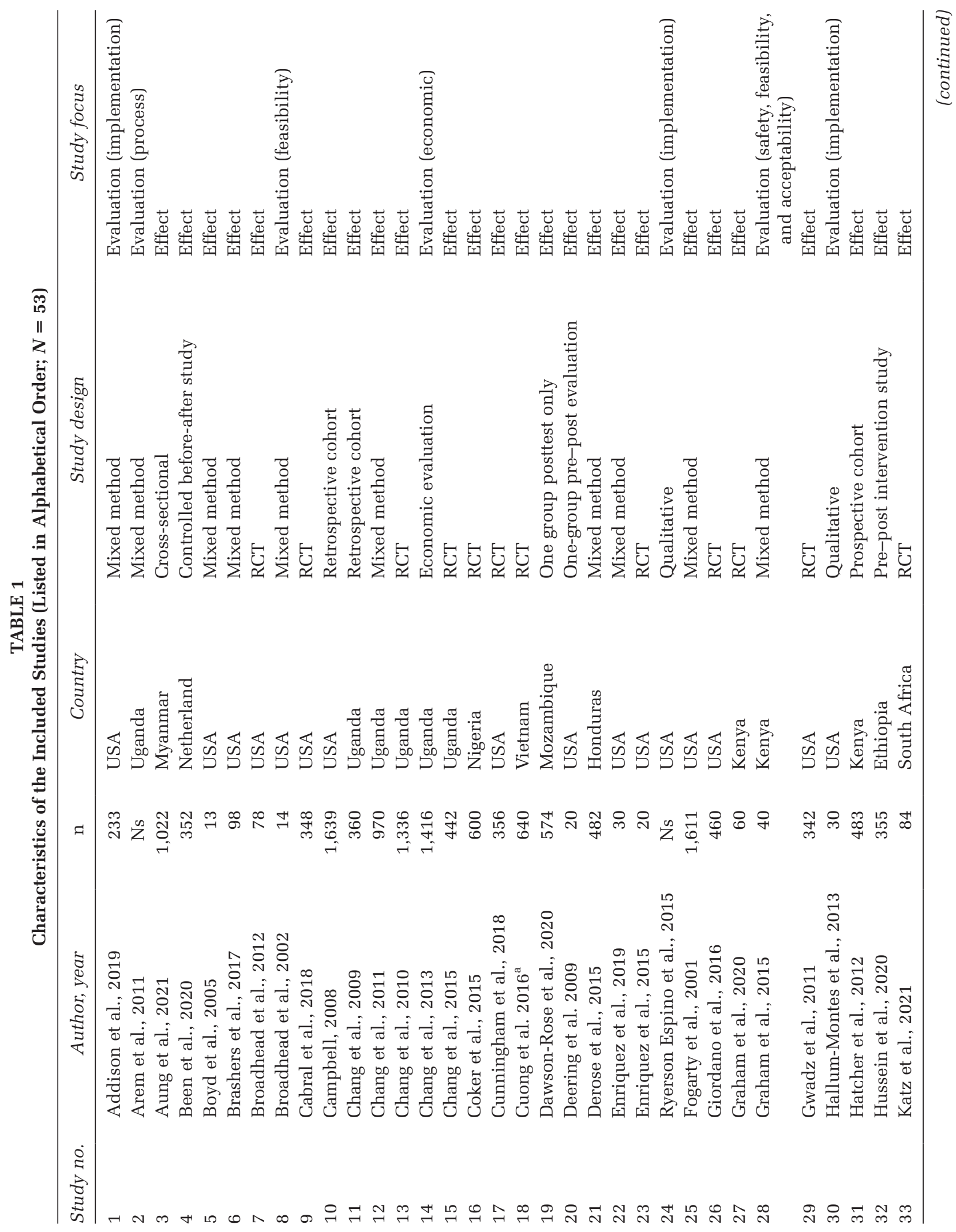

6 HEALTH PROMOTION PRACTICE / Month XXXX 


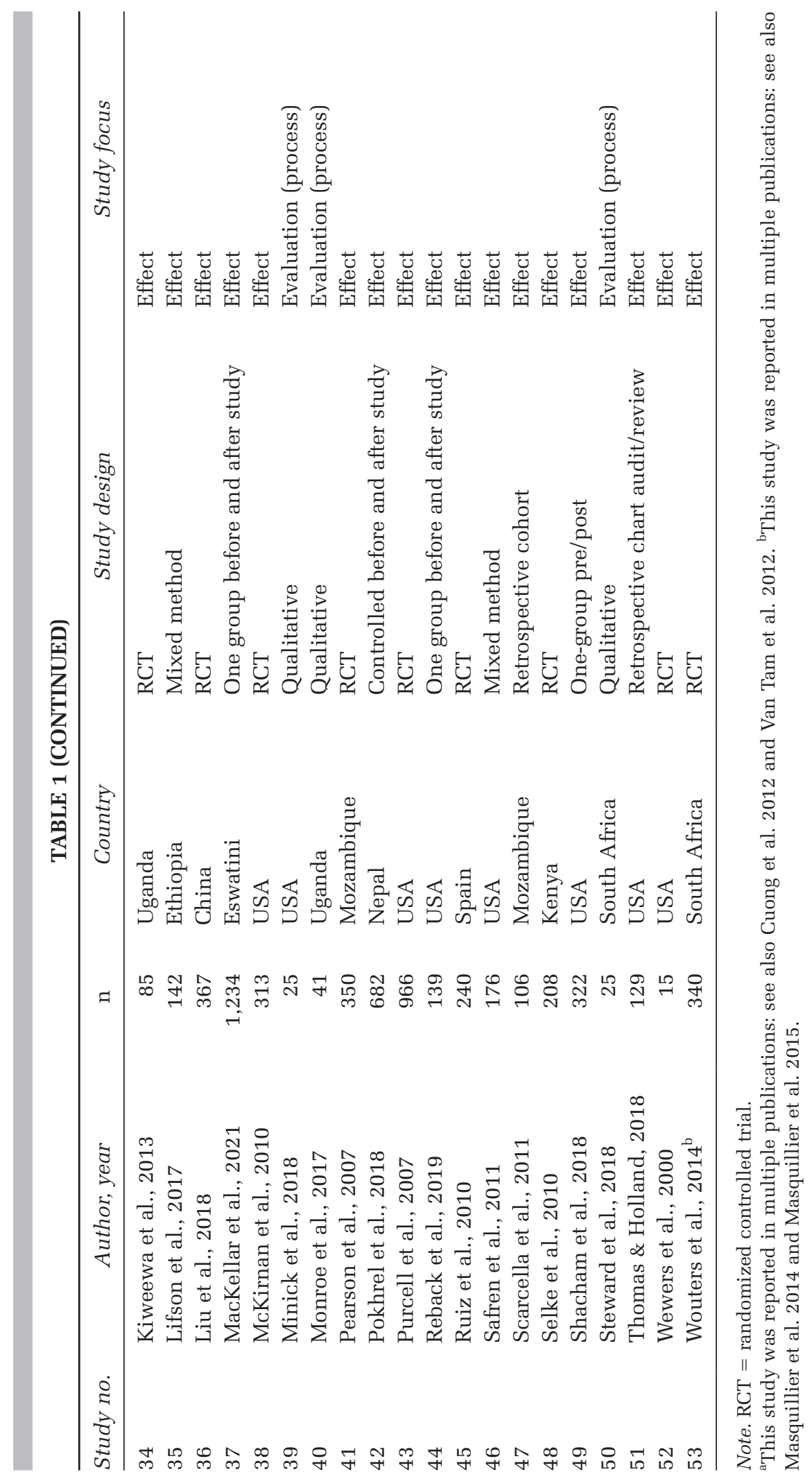

Øgård-Repål et al. / PEER SUPPORT FOR PLHIV 7 
TABLE 2

Summary Characteristics of the Included Studies $(N=53)$

\begin{tabular}{|c|c|c|c|}
\hline Characteristics & All studies $(\mathrm{N}=53)$ & Effect $(\mathrm{n}=43)$ & Evaluation $(\mathrm{n}=10)$ \\
\hline \multicolumn{4}{|l|}{ Year of publication } \\
\hline $2016-2021$ & $23(43)$ & $19(44)$ & $4(40)$ \\
\hline 2010-2015 & $21(40)$ & $16(37)$ & $5(50)$ \\
\hline $2005-2009$ & $6(11)$ & $6(14)$ & \\
\hline $2000-2004$ & $3(6)$ & $2(5)$ & $1(10)$ \\
\hline \multicolumn{4}{|l|}{ Country/setting } \\
\hline Ethiopia & $2(4)$ & $2(5)$ & \\
\hline Kenya & $4(7)$ & $3(7)$ & $1(10)$ \\
\hline Mozambique & $3(6)$ & $3(7)$ & \\
\hline South Africa & $3(6)$ & $2(5)$ & $1(10)$ \\
\hline Uganda & $8(15)$ & $5(12)$ & $3(30)$ \\
\hline USA & $24(45)$ & $19(44)$ & $5(50)$ \\
\hline Other & $9(17)$ & $9(20)$ & \\
\hline \multicolumn{4}{|l|}{ Study design } \\
\hline RCT & $18(34)$ & $18(42)$ & \\
\hline Mixed method & $12(23)$ & $8(19)$ & $4(40)$ \\
\hline Other & $23(43)$ & 17 (39) & $6(60)$ \\
\hline \multicolumn{4}{|l|}{ Gender of participants } \\
\hline Male & $5(9)$ & $4(9)$ & $1(10)$ \\
\hline Female & $6(11)$ & $5(11)$ & $1(10)$ \\
\hline Male and female & $37(70)$ & $30(70)$ & $7(70)$ \\
\hline Male, female, and trans & $4(8)$ & $4(9)$ & \\
\hline Not stated & $1(2)$ & & $1(10)$ \\
\hline
\end{tabular}

Note. The "other" countries were China, Eswatini, Ethiopia, Honduras, Myanmar, Nepal, Netherland, Nigeria, Spain, and Vietnam. RCT $=$ randomized controlled trial.

Other measured outcomes were retention in care, adherence to medical care, mental health, sexual behaviors among PLHIV, quality of life, and stigma. With respect to findings, most studies measuring ART initiation and/ or adherence found a positive effect, but not all. One study measured HIV stigma and three others assessed internalized stigma. However, only two studies reported their results, which found decreased negative feelings and enacted/internalized stigma. Similarly, the results for the other outcomes varied. It is important to bear in mind that the populations, content of peer support, comparisons, and length of follow-up varied.

Evaluation Studies. The other evaluation studies focused on implementation (Studies 1, 24, 30), process (Studies 2, 39, 40, 50), feasibility (Studies 8, 28), and cost (Study 14; Table 1). They included 1824 male and female participants from the United States $(n=5)$, Uganda $(n=3)$, Kenya $(n=1)$, and South Africa $(n=1)$.
Implementation. The three studies on implementation were qualitative $(\mathrm{n}=2)$ and mixed methods $(\mathrm{n}=$ 1) design. They described barriers, challenges, and strategies related to the implementation of peer support interventions as a link to care for PLHIV. One study concluded that the intervention was best suited to newly diagnosed patients (Study 1), while the other two reasoned that the specific settings affected the implementation of peer-based programs and offered considerations on the quality of the training and support of peers and their integration in the delivery of health services (Studies 24, 30).

Process. There were four process evaluations of qualitative $(n=3)$ and mixed-methods $(n=1)$ design. All sought to understand the underlying mechanisms of the intervention results: gain insight into lack of effect (Study 2), clarify positive effects (Study 50), examine how to improve the intervention (Study 39), 


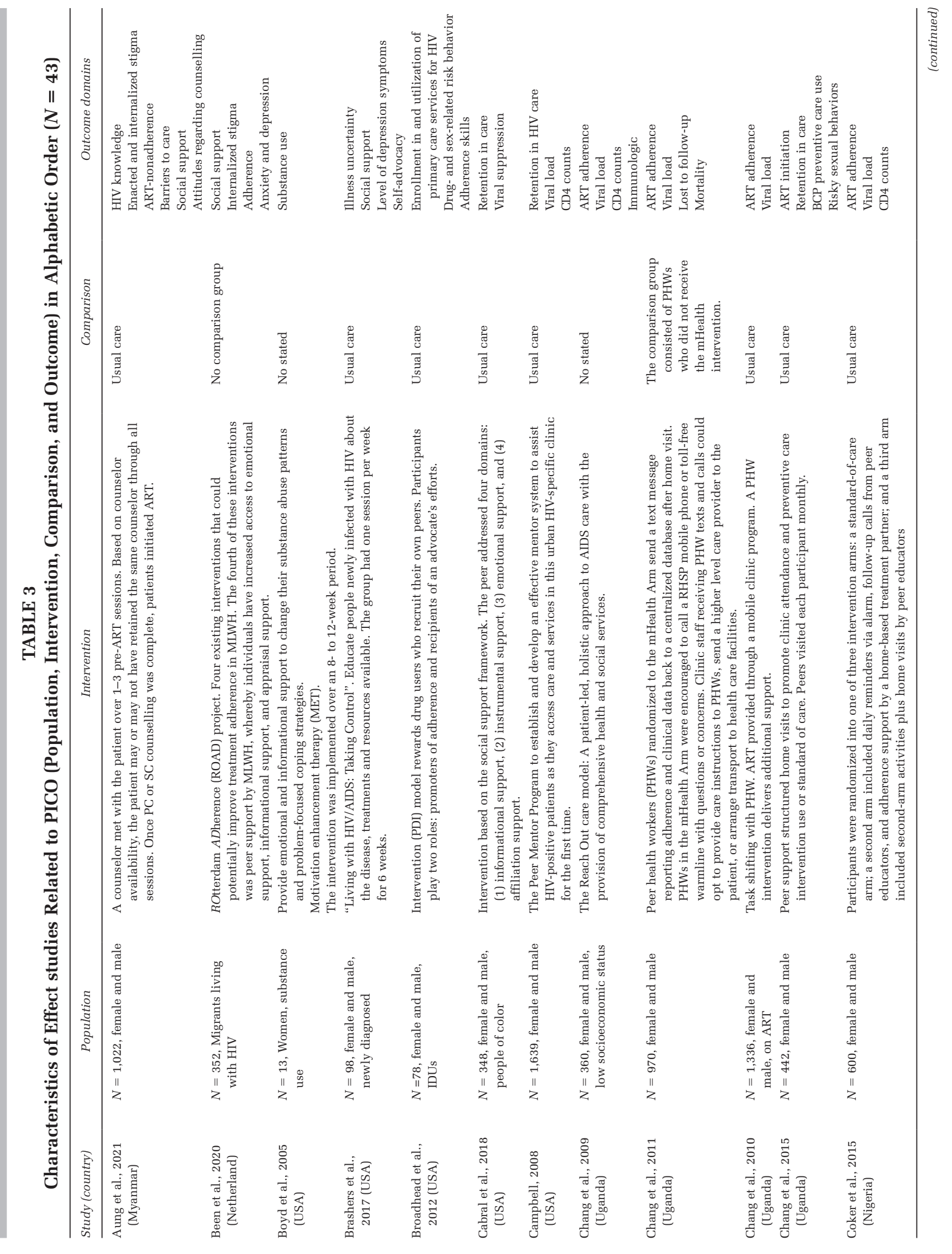

Øgård-Repål et al. / PEER SUPPORT FOR PLHIV 9 


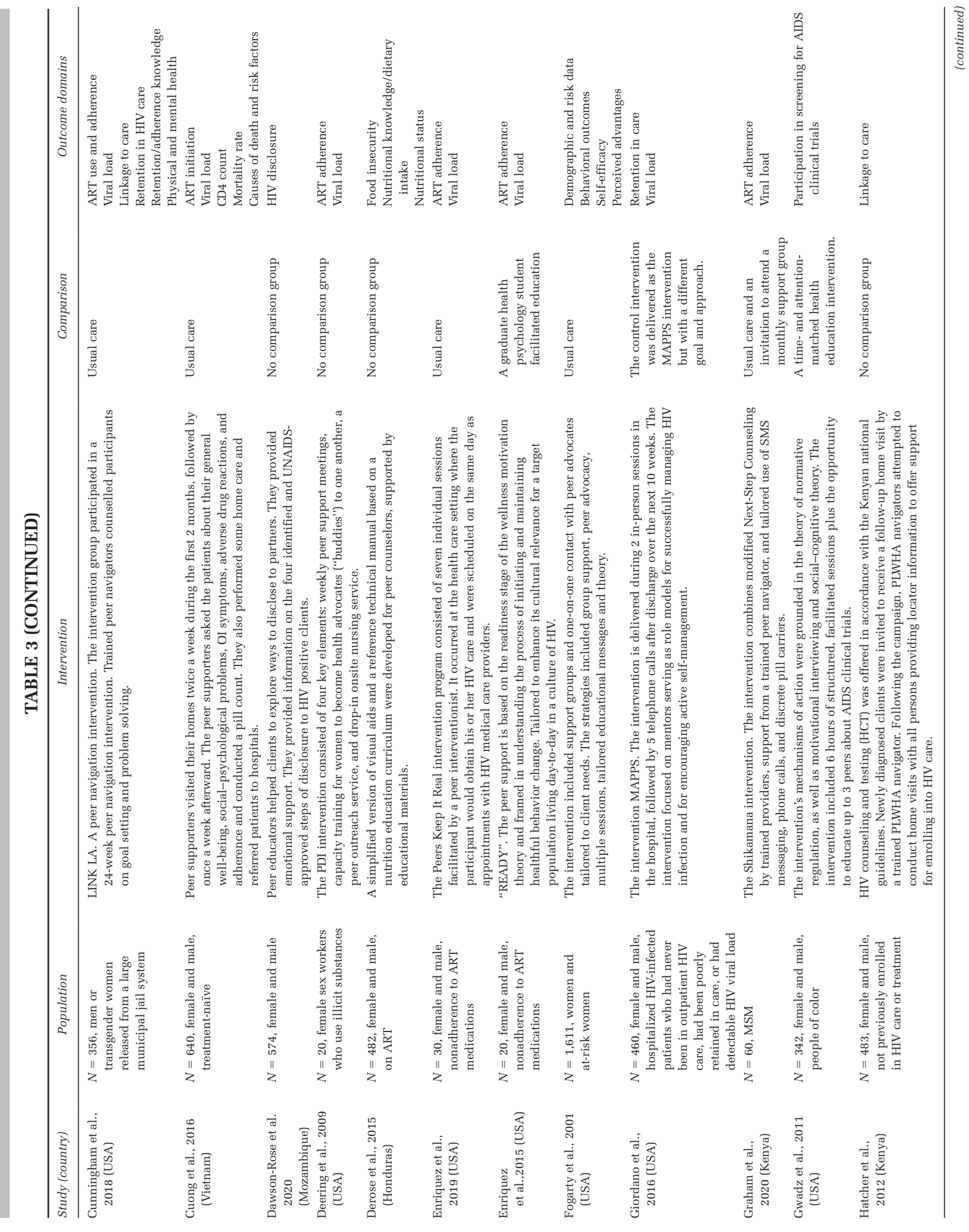




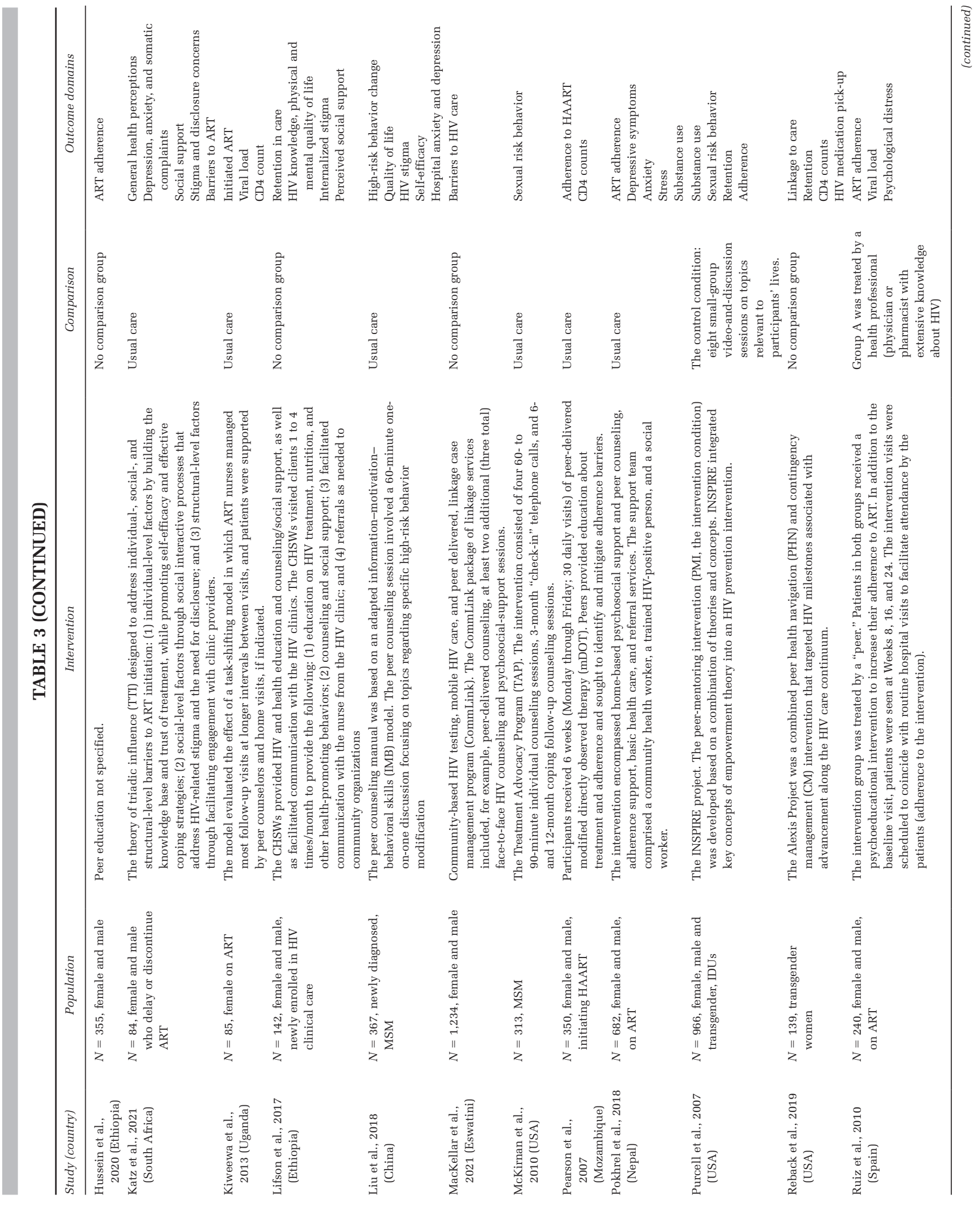




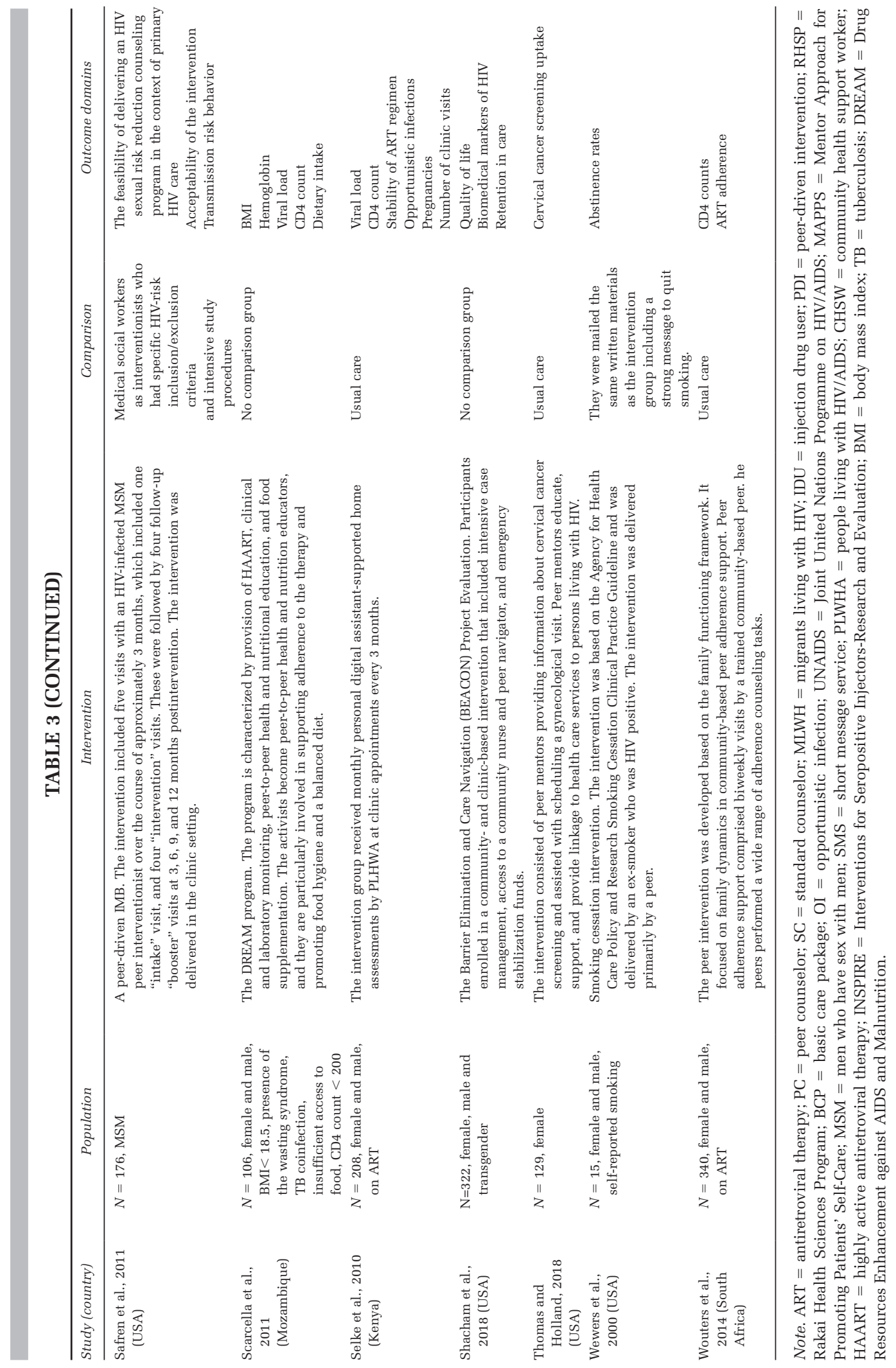


and investigate why and how peer supporters improved client engagement in care (Study 40).

Feasibility. Both studies on feasibility had a mixed methods design. One was related to the willingness and ability of persons who inject drugs to help each other. Findings indicated a high level of willingness and that the peer support intervention increased their adherence to care (Study 8). Another study, which examined the engagement of Kenyan men who have sex with men, concluded that the peer support intervention was feasible and acceptable to the participants (28).

Cost. The economic evaluation analyzed and compared the costs of a peer health worker intervention and a phone peer support intervention (Study 14). While both interventions were evaluated as potentially cost-effective, the threshold analysis suggested that the peer health worker intervention was potentially most cost-effective if it was able to avert 1.5 patients every year from switching to second-line ART.

\section{DISCUSSION}

Our scoping review, aimed to describe the characteristics and results of evaluation research on peer support for PLHIV, identified 53 studies, all published since 2000. Research on peer support for PLHIV has grown rapidly over the past decade. This may reflect the increased life expectancy of PLHIV following the introduction of ART and, hence, peer support becoming a more integrated part of health care services.

\section{Different Populations and Intervention Characteristics}

The 53 studies demonstrated heterogeneity of populations, intervention characteristics, outcomes, and settings investigated in peer support programs. Most studies had both females and males as the priority population for peer support. Other priority groups included people who inject drugs, men who have sex with men, people of color, and individuals with little disposable income, which uncovered a varied priority population. Consistent with the aim of health promotion strategies and the Global Health Sector Strategy on HIV 2016-2021 (WHO, 1986, 2016b), it seems these investigations represent a diversity of needs of PLHIV. However, it is also worth mentioning the low number of studies that included nonbinary genders. This was true despite these individuals being at increased risk of acquiring HIV infection compared with the general population (UNAIDS, 2020). The geographical aspect is noteworthy. A large proportion of the included studies were conducted in low-resource settings and in the U.S. regions heavily affected by the HIV epidemic, while only two were conducted in Europe. This suggests that there is limited interest in this intervention among researchers in Europe.

Furthermore, the most common key intervention function, used in 41 of the interventions, was linked to care and community resources, which is important to strengthen the health care workforce related to HIV. From this perspective, peer support attempts to respond to the needs of PLHIV in priority settings. The key functions "assistance in daily management" and "linkage to care and community resources" have the flexibility to engage those living with HIV in the process of planning peer support. This involvement ensures that peer support fits the priority population. A setting-specific approach acknowledges that low-resource and highresource settings have different needs, which is evident in the context of studies.

\section{A Reflection on Measured Outcomes}

Biological markers, such as viral load, CD4 counts, and adherence to ART, were the most frequently measured outcomes in the included studies. A recent systematic review detailed findings on these outcomes (Berg et al., 2021). Only four of our studies measured stigma as the primary outcome. This is despite stigma being a known barrier to HIV treatment and care (Relf et al., 2021), with studies showing that it affects the degree of disclosure, followed by decreased social support and health-seeking behavior (Smith et al., 2008).

It is important to measure the effect of peer support on perceived stigma. Research shows that interventions that increased linkages to care and community resources, as well as social and emotional support, were able to facilitate improvements in mental health status and had the potential to enable those living with HIV to overcome the effects of anticipated and internalized stigma (Garrido-Hernansaiz \& Alonso-Tapia, 2017). Thus, social support from peers may be a resource when people experience stress in response to stigma (Dulin et al., 2018; Dunbar et al., 2020; Earnshaw et al., 2015).

We also found a need to clarify the support needed by PLHIV as individuals living with a CLLC. Although anticipated and/or experienced stigma might affect their general efforts to seek support, the included studies indicate that meeting a peer supporter may contribute to social support. However, few studies have measured whether and how peer support affects aspects of mental health and quality of life as primary outcomes, despite 
the high rates of documented mental health disorders among PLHIV (Brandt, 2009; Parcesepe et al., 2018). This could be related to the scant amount of peer support related to chronic diseases as a key function, according to the definition of ongoing chronic support by the Peers for Progress program (Fisher, 2014; Fisher et al., 2018). Despite the large number of studies that support selfmanagement, social and emotional support, and linkage to HIV care, few studies have reported peer support as a long term, flexible outreach program.

\section{What Defines Peers?}

We found little uniformity in terms of both the terminology and practice of peer support. We identified 13 different labels/names for peer supporters, with the most frequently used label being "peer'. This is somewhat surprising considering our narrow inclusion criteria. In their review of "Peer Interventions to Promote Health: Conceptual Considerations," Simoni et al. (2011) proposed the term "peer" as standard terminology with an extended definition consisting of four elements: (1) peers share key personal characteristics, circumstances or experiences with the priority group; (2) the benefits of a peer intervention derive largely from their status as peers; (3) peers do not need professional training; and (4) peers function according to a specific role. The first element coincides with a definition proposed by Dennis (2003). Still, Simoni et al. (2011) used a clearer conceptualization to distinguish peer work interventions from work by others involved in services. In this terminology, the definition of Dennis (2003) might have a wider reach than Simoni's, although Simoni's definition is more focused on peer roles. The variation of labels discovered across the included studies in this review may suggest that different labels fit different interventions. We categorized the key functions of peer support and found that three key functions were part of most interventions-only one focused on ongoing support related to chronic disease and two studies lacked information on key functions. It is necessary to understand the characteristics and primary key functions of peer supporters. When the intervention characteristics are insufficiently described or poorly reported, and the intervention subsequently appears to exist in many variants under different labels, it becomes harder to understand what is meant when "peer support" and similar terms are used.

\section{Agreements and Disagreements With Other Studies or Reviews}

Several reviews on peer support interventions for PLHIV have been conducted. While focusing on separate aspects, these largely mirror our findings. First, Simoni et al. (2011) conducted a systematic review to investigate the efficacy of different types of peer support in HIV/AIDS patients. The review resolved some effects of peer interventions, but heterogeneity in populations and outcomes affected the ability to draw conclusions. These authors and authors of a review published a decade later (Berg et al., 2021) state that additional, carefully designed studies are required to investigate the effectiveness of peers and the conditions that need to be present to ensure successful interventions. This reflects our finding that various intervention characteristics, settings, and outcomes challenge the ability to compare interventions. Genberg et al. (2016) conducted a systematic review of peer interventions to improve engagement in care, indicating that peers had a mixed impact on ART adherence, viral suppression, and mortality. Although peer interventions had a positive effect on linkage to and retention in care, a limited number of studies have measured these outcomes. Decroo et al. (2012) published a review that examined whether expert patients were an untapped resource of ART provision in sub-Saharan Africa. Findings indicated that PLHIV can serve as a resource in the provision of ART in this region, which is promising in this high-epidemic area. Notably, we have identified no reviews on the implementation of peer support, process evaluation, or cost analysis.

\section{Implications}

The increased number of publications on peer support for PLHIV over the last decade has shown a growing interest in this topic. Despite this, we recognize the need for more studies in Europe and sub-Saharan Africa. Only two studies were from Europe, and less than $40 \%$ of the included studies were conducted in sub-Saharan Africa, which is a high-epidemic area of HIV, identified by the WHO as a priority population (WHO, 2016b). There have been no studies from Russia, which is one of the few countries with growing HIV incidence rates. Areas such as sub-Saharan Africa and Russia are in need of fasttrack action (WHO, 2016b), and research evidence from other areas with comparable populations can be transferred to these. However, there will be a lack of settingspecific knowledge. A handful of forthcoming studies on peer support for PLHIV are registered at ClincalTrials. gov. They mostly relate to the prevention of HIV, which is promising; however, few prioritize the population in sub-Saharan Africa.

Our results show that the most common key characteristics of peer support are linkage to care and community resources, assistance in daily management, and social and emotional support. These are appropriate 
for the priority population and the settings of the existing interventions and can, arguably, have an impact on stigma, mental health, and quality of life. Our results suggest a broader scope when the effects and experiences of peer support are measured in relation to living with HIV, knowing that new needs arise throughout life when living with a CLLC (Fisher, 2014; Fisher et al., 2018). As noted, our results align with existing global strategies and guidelines, and have relevance for policy makers and health care providers. As indicated by other reviews (Berg et al., 2021), the results support that peer support can help shoulder existing services. The Global Health Sector Strategy on HIV 2016-2020 recommends an integrated care package designed to meet people's needs and preferences and increase self-management related to CLLC. Hence, peer support is a type of care package that can meet the various needs of PLHIV. Further focus on interventions addressing secondary prevention related to noncommunicable diseases as part of this package is recommended.

Because of its broad aim and inclusion of studies, this review is summative in nature and provides an opportunity for detailed analysis of effect studies in particular. Our results further demonstrate the scarcity of studies on the implementation, process, and cost analyses. These are important perspectives for researchers and health care entities in consideration of improvement of peer support services.

\section{Strengths and Limitations}

The systematic approach regarding searches, selection, and data extraction is the main strength of our scoping review, although a limitation of the review is the absence of studies in languages other than Scandinavian and English. Our framework helped us to be consistent in the approach, and the data analyses made it possible to identify and maintain consistency for all categories. The broad scope of this review, along with the large number of included studies with diverse findings, limited the opportunity to draw firm conclusions. This review provides a comprehensive overview of the research field on the evaluation of peer support for PLHIV. A main limitation was that the included studies had several labels for peer supporters that were previously unknown to the reviewers. It is possible that this could have affected the search strategy, and we might have missed some relevant studies.

\section{CONCLUSIONS}

This scoping review documented an increased research interest in peer support for PLHIV, although it revealed gaps in where the research was conducted, outcomes measured, and prioritized function of peer support related to chronic care. With about 25.4 million people accessing ART, the need for support related to retention in care and chronic care is increasing. The gaps in the prioritized functions of peer support have implications for further research. The flexibility of the peer support role related to settings, health outcomes, and populations appears to complement health care services with regard to the different needs of PLHIV.

\section{ORCID iDs}

Anita Øgård-Repål iD https://orcid.org/0000-0002-7037-7650

Mariann Fossum (iD https://orcid.org/0000-0003-4162-4277

\section{Supplemental Material}

Supplemental material for this article is available online at https:// journals.sagepub.com/home/hpp.

\section{REFERENCES}

Addison, D., Baim-Lance, A., Suchman, L., Katz, B., Swain, C. A., Piersanti, K., Steinbock, C., Sawicki, S., Agins, B., \& Nash, D., \& NYLinks Implementation Team. (2019). Factors influencing the successful implementation of HIV linkage and retention interventions in healthcare agencies across New York State. AIDS and Behavior, 23(Suppl. 1), 105-114. https://doi.org/10.1007/s10461-018-2060-2

Arem, H., Nakyanjo, N., Kagaayi, J., Mulamba, J., Nakigozi, G., Serwadda, D., Quinn, T. C., Gray, R. H., Bollinger, R. C., Reynolds, S. J., \& Chang, L. W. (2011). Peer health workers and AIDS care in Rakai, Uganda: A mixed methods operations research evaluation of a cluster-randomized trial. AIDS Patient Care and STDs, 25(12), 719-724. https://doi.org/10.1089/apc.2010.0349

Arksey, H., \& O’Malley, L. (2005). Scoping studies: Towards a methodological framework. International Journal of Social Research Methodology, 8(1), 19-32. https://doi.org/10.1080/136455703200 0119616

Aung, S., Hardy, N., Chrysanthopoulou, S., Htun, N., Kyaw, A., Tun, M. S., \& Rana, A. (2021). Evaluation of peer-to-peer HIV counseling in Myanmar: A measure of knowledge, adherence, and barriers. AIDS Care. Advance online publication. https://doi.org/10. 1080/09540121.2021.1902929

Been, S. K., van de Vijver, D. A. M. C., Smit, J., Bassant, N., Pogány, K., Stutterheim, S. E., \& Verbon, A. (2020). Feasibility of four interventions to improve treatment adherence in migrants living with HIV in The Netherlands. Diagnostics (Basel), 10(11), 980. https:// doi.org/10.3390/diagnostics10110980

Berg, R. C., Page, S., \& Øgård-Repål, A. (2021). The effectiveness of peer-support for people living with HIV: A systematic review and meta-analysis. PLOS ONE, 16(6), Article e0252623. https://doi. org/10.1371/journal.pone.0252623

Berg, R. C., \& Ross, M. W. (2014). The second closet: A qualitative study of HIV stigma among seropositive gay men in a southern U.S. city. International Journal of Sexual Health, 26(3), 186-199. https://doi.org/10.1080/19317611.2013.853720

Booth, A., Sutton, A., \& Papaioannou, D. (2016). Systematic approaches to a successful literature review (2nd ed.). Sage. 
Boucher, L. M., Liddy, C., Mihan, A., \& Kendall, C. (2020). Peer-led self-management interventions and adherence to antiretroviral therapy among people living with HIV: A systematic review. AIDS and Behavior, 24(4), 998-1022. https://doi.org/10.1007/s10461019-02690-7

Boyd, M. R., Moneyham, L., Murdaugh, C., Phillips, K. D., Tavakoli, A., Jackwon, K., Jackson, N., \& Vyavaharkar, M. (2005). A peerbased substance abuse intervention for HIV + rural women: A pilot study. Archives of Psychiatric Nursing, 19(1), 10-17. https://doi. org/10.1016/j.apnu.2004.11.002

Brandt, R. (2009). The mental health of people living with HIV/AIDS in Africa: A systematic review. African Journal of AIDS Research, 8(2), 123-133. https://doi.org/10.2989/AJAR.2009.8.2.1.853

Brashers, D. E., Basinger, E. D., Rintamaki, L. S., Caughlin, J. P., \& Para, M. (2017). Taking control: The efficacy and durability of a peer-led uncertainty management intervention for people recently diagnosed with HIV. Health Communication, 32(1), 11-21. https:// doi.org/10.1080/10410236.2015.1089469

Broadhead, R. S., Borch, C., van Hulst, Y., Gauchat, G., Tehrani, S., Stringer, K. L., Heckathorn, D. D., \& Altice, F. L. (2012). Relying on injection drug users to access and adhere to HIV therapeutics: Bittersweet lessons using respondent-driven sampling and a peerdriven intervention. Journal of Drug Issues, 42(2), 127-146. https:// doi.org/10.1177/0022042612446581

Broadhead, R. S., Heckathorn, D. D., Altice, F. L., van Hulst, Y., Carbone, M., Friedland, G. H., O'Connor, P. G., \& Selwyn, P. A. (2002). Increasing drug users' adherence to HIV treatment: Results of a peerdriven intervention feasibility study. Social Science \& Medicine, 55(2), 235-246. https://doi.org/10.1016/S0277-9536(01)00167-8

Cabral, H. J., Davis-Plourde, K., Sarango, M., Fox, J., Palmisano, J., \& Rajabiun, S. (2018). Peer Support and the HIV Continuum of Care: Results from a Multi-Site Randomized Clinical Trial in Three Urban Clinics in the United States. AIDS and Behavior, 22(8), 2627-2639. https://doi.org/10.1007/s10461-017-1999-8

Campbell, K. M. (2008). An analysis of the effects of a peer mentor program and other factors on HIV patients' retention in care and clinical outcomes at Thomas Street Health Clinic, Houston Texas [Networked Digital Library of Theses and Dissertations]. University of Texas School of Public Health, Houston, Texas.

Chang, L., Nakigozi, G., Billioux, V., Gray, R., Serwadda, D., Quinn, T., Wawer, M., Bollinger, R., \& Reynolds, S. (2015). Effectiveness of peer support on care engagement and preventive care intervention utilization among pre-antiretroviral therapy, HIV-infected adults in Rakai, Uganda: A randomized trial. AIDS and Behavior, 19(10), 1742-1751. https://doi.org/10.1007/s10461-015-1159-y

Chang, L. W., Alamo, S., Guma, S., Christopher, J., Suntoke, T., Omasete, R., Montis, J. P., Quinn, T. C., Juncker, M., \& Reynolds, S. J. (2009). Two-year virologic outcomes of an alternative AIDS care model: Evaluation of a peer health worker and nurse-staffed community-based program in Uganda. JAIDS Journal of Acquired Immune Deficiency Syndromes, 50(3), 276-282. https://doi. org/10.1097/QAI.0b013e3181988375

Chang, L. W., Kagaayi, J., Arem, H., Nakigozi, G., Ssempijja, V., Serwadda, D., Quinn, T. C., Gray, R. H., Bollinger, R. C., \& Reynolds, S. J. (2011). Impact of a mHealth intervention for peer health workers on AIDS care in rural Uganda: A mixed methods evaluation of a cluster-randomized trial. AIDS and Behavior, 15(8), 1776-1784. https://doi.org/10.1007/s10461-011-9995-x
Chang, L. W., Kagaayi, J., Nakigozi, G., Serwada, D., Quinn, T. C., Gray, R. H., Bollinger, R. C., Reynolds, S. J., \& Holtgrave, D. (2013). Cost analyses of peer health worker and mHealth support interventions for improving AIDS care in Rakai, Uganda. AIDS Care, 25(5), 652-656. https://doi.org/10.1080/09540121.2012.722600

Chang, L. W., Kagaayi, J., Nakigozi, G., Ssempijja, V., Packer, A. H., Serwadda, D., Quinn, T. C., Gray, R. H., Bollinger, R. C., \& Reynolds, S. J. (2010). Effect of peer health workers on AIDS care in Rakai, Uganda: A cluster-randomized trial. PLOS ONE, 5(6), Article e10923. https://doi.org/10.1371/journal.pone.0010923

Chaudoir, S. R., \& Fisher, J. D. (2018). Stigma and the "social epidemic" of HIV: understanding bidirectional mechanisms of risk and resilience (1st ed.). Oxford University Press.

Clapton, J., Rutter, D., \& Sharif, N. (2009). SCIE systematic mapping guidance. Social Care Institute for Excellence. http://www.scie.org. uk/publications/researchresources/rr03.pdf

Coker, M., Etiebet, M. A., Chang, H., Awwal, G., Jumare, J., Musa, B. M., Babashani, M., Habib, A. G., Dakum, P., Abimiku, A. G., Charurat, M. E., Blattner, W. A., Eng, M., \& Ndembi, N. (2015). Socio-demographic and adherence factors associated with viral load suppression in HIV-infected adults initiating therapy in Northern Nigeria: A randomized controlled trial of a peer support intervention. Current HIV Research, 13(4), 279-285. https://doi. org/10.2174/1570162X13666150407143838

Cunningham, W. E., Weiss, R. E., Nakazono, T., Malek, M. A., Shoptaw, S. J., Ettner, S. L., \& Harawa, N. T. (2018). Effectiveness of a peer navigation intervention to sustain viral suppression among HIV-positive men and transgender women released from jail: The LINK LA randomized clinical trial. JAMA Internal Medicine, 178(4), 542-553. https://doi.org/10.1001/jamainternmed.2018.0150

Cuong, D. D., Sonnerborg, A., Van Tam, V., El-Khatib, Z., Santacatterina, M., Marrone, G., Chuc, N. T., Diwan, V., Thorson, A., Le, N. K., An, P. N., \& Larsson, M. (2016). Impact of peer support on virologic failure in HIV-infected patients on antiretroviral therapy: A cluster randomized controlled trial in Vietnam. BMC Infectious Diseases, 16(1), Article 759. https://doi.org/10.1186/ s12879-016-2017-x

Cuong, D. D., Thorson, A., Sönnerborg, A., Hoa, N. P., Chuc, N. T. K., Phuc, H. D., \& Larsson, M. (2012). Survival and causes of death among HIV-infected patients starting antiretroviral therapy in north-eastern Vietnam, Scandinavian. Journal of Infectious Diseases, 44(3), 201-208. https://doi.org/10.3109/00365548.2011. 631937

Dave, S., Peter, T., Fogarty, C., Karatzas, N., Belinsky, N., \& Pant Pai, N. (2019). Which community-based HIV initiatives are effective in achieving UNAIDS 90-90-90 targets? A systematic review and meta-analysis of evidence (2007-2018). PLOS ONE, 14(7), Article e0219826. https://doi.org/10.1371/journal.pone.0219826

Dawson-Rose, C., Gutin, S. A., Mudender, F., Hunguana, E., \& Kevany, S. (2020). Effects of a peer educator program for HIV status disclosure and health system strengthening: Findings from a clinic-based disclosure support program in Mozambique. PLOS ONE, 15(5), Article e0232347. https://doi.org/10.1371/journal.pone.0232347

Decroo, T., Van Damme, W., Kegels, G., Remartinez, D., \& Rasschaert, F. (2012). Are expert patients an untapped resource for ART provision in sub-Saharan Africa? AIDS Research and Treatment, 2012, Article 749718. https://doi.org/10.1155/2012/749718 
Deering, K. N., Shannon, K., Sinclair, H., Parsad, D., Gilbert, E., \& Tyndall, M. W. (2009). Piloting a peer-driven intervention model to increase access and adherence to antiretroviral therapy and HIV care among street-entrenched HIV-positive women in Vancouver. AIDS Patient Care and STDs, 23(8), 603-609. https://doi. org/10.1089/apc.2009.0022

Dennis, C.-L. (2003). Peer support within a health care context: a concept analysis. International Journal of Nursing Studies, 40(3), 321-332. https://doi.org/10.1016/S0020-7489(02)00092-5

Derose, K. P., Felician, M., Han, B., Palar, K., Ramirez, B., Farias, H., \& Martinez, H. (2015). A pre-post pilot study of peer nutritional counseling and food insecurity and nutritional outcomes among antiretroviral therapy patients in Honduras. BMC Nutrition, 1, Article 21. https://doi.org/10.1186/s40795-015-0017-7

Dulin, A. J., Dale, S. K., Earnshaw, V. A., Fava, J. L., Mugavero, M. J., Napravnik, S., Hogan, J. W., Carey, M. P., \& Howe, C. J. (2018). Resilience and HIV: A review of the definition and study of resilience. AIDS Care, 30(Suppl. 5), S6-S17. https://doi.org/10.1080/0 9540121.2018.1515470

Dunbar, W., Labat, A., Raccurt, C., Sohler, N., Pape, J. W., Maulet, N., \& Coppieters, Y. (2020). A realist systematic review of stigma reduction interventions for HIV prevention and care continuum outcomes among men who have sex with men. International Journal of STD and AIDS, 31(8), 712-723. https://doi. org/10.1177/0956462420924984

Earnshaw, V., Lang, S., Lippitt, M., Jin, H., \& Chaudoir, S. (2015). HIV stigma and physical health symptoms: Do social support, adaptive coping, and/or identity centrality act as resilience resources? AIDS and Behavior, 19(1), 41-49. https://doi. org/10.1007/s10461-014-0758-3

Enriquez, M., Cheng, A.-L., McKinsey, D., Farnan, R., Ortego, G., Hayes, D., Miles, L., Reese, M., Downes, A., Enriquez, A., Akright, J., \& El Atrouni, W. (2019). Peers keep it real: Re-engaging adults in HIV care. Journal of the International Association of Providers of AIDS Care, 18. https://doi.org/10.1177/2325958219838858

Enriquez, M., Cheng, A. L., Banderas, J., Farnan, R., Chertoff, K., Hayes, D., Ortego, G., Moreno, J., Peterson, J., \& McKinsey, D. (2015). A peer-led HIV medication adherence intervention targeting adults linked to medical care but without a suppressed viral load. Journal of the International Association of Providers of AIDS Care, 14(5), 441-448. https://doi. org $/ 10.1177 / 2325957414558301$

Fisher, E. B. (2014). Global evidence for peer support: Humanizing health care (Report). Peers for Progress. https://www.ipfcc.org/ bestpractices/global-evidence-for-peer-support.pdf

Fisher, E. B., Tang, P. Y., Coufal, M. M., Liu, Y., \& Jia, W. (2018). Peer support. In T. P. Daaleman \& M. R. Helton (Eds.), Chronic illness care: Principles and practice (pp. 133-146). Springer.

Fogarty, L. A., Heilig, C. M., Armstrong, K., Cabral, R., Galavotti, C., Gielen, A., \& Green, B. M. (2001). Long-term effectiveness of a peer-based intervention to promote condom and contraceptive use among HIV-positive and at-risk women. Public Health Reports, 116(Suppl. 1), 103-119. https://doi.org/10.1093/phr/ 116.S1.103

Garrido-Hernansaiz, H., \& Alonso-Tapia, J. (2017). Social support in newly diagnosed people living with HIV: Expectations and satisfaction along time, predictors, and mental health correlates.
Journal of the Association of Nurses in AIDS Care, 28(6), 849-861. https://doi.org/10.1016/j.jana.2017.06.007

Genberg, B. L., Shangani, S., Sabatino, K., Rachlis, B., Wachira, J., Braitstein, P., \& Operario, D. (2016). Improving engagement in the HIV care cascade: A systematic review of interventions involving people living with HIV/AIDS as peers. AIDS and Behavior, 20(10), 2452-2463. https://doi.org/10.1007/s10461-016-1307-z

Giordano, T. P., Cully, J., Amico, K. R., Davila, J. A., Kallen, M. A., Hartman, C., Wear, J., Buscher, A., \& Stanley, M. (2016). A randomized trial to test a peer mentor intervention to improve outcomes in persons hospitalized with HIV infection. Clinical Infectious Diseases, 63(5), 678-686. https://doi.org/10.1093/cid/ciw322

Graham, S. M., Micheni, M., Chirro, O., Nzioka, J., Secor, A. M., Mugo, P. M., Kombo, B., van der Elst, E. M., Operario, D., Amico, K. R., Sanders, E. J., \& Simoni, J. M. (2020). A randomized controlled trial of the Shikamana intervention to promote antiretroviral therapy adherence among gay, bisexual, and other men who have sex with men in Kenya: Feasibility, acceptability, safety and initial effect size. AIDS and Behavior, 24(7), 2206-2219. https:// doi.org/10.1007/s10461-020-02786-5

Graham, S. M., Micheni, M., Kombo, B., van der Elst, E. M., Mugo, P. M., Kivaya, E., Aunon, F., Kutner, B., Sanders, E. J., \& Simoni, J. M. (2015). Development and pilot testing of an intervention to promote care engagement and adherence among HIV-positive Kenyan MSM. AIDS, 29(Suppl. 3), S241-S249. https://doi. org/10.1097/QAD.0000000000000897

Grønningsæter, A. B., \& Hansen, I. L. S. (2018). Aging with HIV. https://www.fafo.no/zoo-publikasjoner/summaries/item/agingwith-hiv

Gwadz, M., Leonard, N., Cleland, C. M., Riedel, M., Banfield, A., \& Mildvan, D. (2011). The effect of peer-driven intervention on rates of screening for AIDS clinical trials among African Americans and Hispanics. American Journal of Public Health, 101(10), 10962011. https://doi.org/10.2105/AJPH.2007.196048e

Hallum-Montes, R., Morgan, S., Rovito, H. M., Wrisby, C., \& Anastario, M. P. (2013). Linking peers, patients, and providers: A qualitative study of a peer integration program for hard-to-reach patients living with HIV/AIDS. AIDS Care, 25(8), 968-972. https:// doi.org/10.1080/09540121.2012.748869

Hatcher, A., Turan, J., Leslie, H., Kanya, L., Kwena, Z., Johnson, M., Shade, S., Bukusi, E., Doyen, A., \& Cohen, C. (2012). Predictors of linkage to care following community-based HIV counseling and testing in rural Kenya. AIDS and Behavior, 16(5), 1295-1307. https://doi.org/10.1007/s10461-011-0065-1

Hussein, M., Dibaba, B., \& Wondu, Y. (2020). Factors influencing effectiveness of peer education against nonadherence to antiretroviral therapy among adult people living with HIV/AIDS: A pre-post intervention study in Arsi Zone, Ethiopia. HIV/AIDS (Auckland, N.Z.), 12, 1-7. https://doi.org/10.2147/HIV.S228330

Katz, I. T., Bogart, L. M., Fitzmaurice, G. M., Staggs, V. S., Gwadz, M. V., Bassett, I. V., Cross, A., Courtney, I., Tsolekile, L., Panda, R., Steck, S., Bangsberg, D. R., Orrell, C., \& Goggin, K. (2021). The treatment ambassador program: A highly acceptable and feasible community-based peer intervention for South Africans living with HIV who delay or discontinue antiretroviral therapy. AIDS and Behavior, 25(4), 1129-1143. http://doi.org/10.1007/s10461-020-03063-1

Kiweewa, F. M., Wabwire, D., Nakibuuka, J., Mubiru, M., Bagenda, 
D., Musoke, P., Fowler, M. G., \& Antelman, G. (2013). Noninferiority of a task-shifting HIV care and treatment model using peer counselors and nurses among Ugandan women initiated on ART: Evidence from a randomized trial. JAIDS Journal of Acquired Immune Deficiency Syndromes, 63(4), e125-e132. https://doi. org/10.1097/QAI.0b013e3182987ce6

Levac, D., Colquhoun, H., \& O’Brien, K. K. (2010). Scoping studies: Advancing the methodology. Implementation Science, 5(1), Article 69. https://doi.org/10.1186/1748-5908-5-69

Liamputtong, P. (2007). Researching the vulnerable: A guide to sensitive research methods. Sage.

Lifson, A. R., Workneh, S., Hailemichael, A., Demisse, W., Slater, L., \& Shenie, T. (2017). Implementation of a peer HIV community support worker program in rural Ethiopia to promote retention in care. Journal of the International Association of Providers of AIDS Care, 16(1), 75-80. https://doi.org/10.1177/2325957415614648

Liu, Y., Vermund, S. H., Ruan, Y., Liu, H., Rivet Amico, K., Simoni, J. M., Shepherd, B. E., Shao, Y., \& Qian, H. Z. (2018). Peer counselling versus standard-of-care on reducing high-risk behaviours among newly diagnosed HIV-positive men who have sex with men in Beijing, China: A randomized intervention study. Journal of the International AIDS Society, 21(2), Article e25079. https://doi. org/10.1002/jia2.25079

MacKellar, D., Williams, D., Dlamini, M., Byrd, J., Dube, L., Mndzebele, P., Mazibuko, S., Pathmanathan, I., Tilahun, E., \& Ryan, C. (2021). Overcoming barriers to HIV care: Findings from a peerdelivered, Community-Based, Linkage Case Management Program (CommLink), Eswatini, 2015-2018. AIDS and Behavior, 25(5), 1518-1531. https://doi.org/10.1007/s10461-020-02991-2

Masquillier, C., Wouters, E., Mortelmans, D., \& Booysen, F. l. R. (2014). Families as catalysts for peer adherence support in enhancing hope for people living with HIV/AIDS in South Africa. Journal of the International AIDS Society, 17, 18802. https://doi. org/10.7448/IAS.17.1.18802

Masquillier, C., Wouters, E., Mortelmans, D., \& Booysen, F. l. R. (2015). The impact of community support initiatives on the stigma experienced by people living with HIV/AIDS in South Africa. AIDS and Behavior, 19, 214-226. https://doi.org/10.1007/s10461-0140865-1

McKirnan, D. J., Tolou-Shams, M., \& Courtenay-Quirk, C. (2010). The treatment advocacy program: A randomized controlled trial of a peer-led safer sex intervention for HIV-infected men who have sex with men. Journal of Consulting and Clinical Psychology, 78(6), 952-963. https://doi.org/10.1037/a0020759

Minick, S. G., May, S. B., Amico, K. R., Cully, J., Davila, J. A., Kallen, M. A., \& Giordano, T. P. (2018). Participants' perspectives on improving retention in HIV care after hospitalization: A post-study qualitative investigation of the MAPPS study. PLOS ONE, 13(8), e0202917. https://doi.org/10.1371/journal.pone.0202917

Monroe, A., Nakigozi, G., Ddaaki, W., Bazaale, J. M., Gray, R. H., Wawer, M. J., Reynolds, S. J., Kennedy, C. E., \& Chang, L. W. (2017). Qualitative insights into implementation, processes, and outcomes of a randomized trial on peer support and HIV care engagement in Rakai, Uganda. BMC Infectious Diseases, 17(1), Article 54. https:// doi.org/10.1186/s12879-016-2156-0

Ouzzani, M., Hammady, H., Fedorowicz, Z., \& Elmagarmid, A. (2016). Rayyan - a web and mobile app for systematic reviews. Systematic Reviews, 5, 210. https://doi.org/10.1186/s13643-016-0384-4
Pantelic, M., Steinert, J. I., Park, J., Mellors, S., \& Murau, F. (2019). "Management of a spoiled identity": Systematic review of interventions to address self-stigma among people living with and affected by HIV. BMJ Global Health, 4(2), e001285. https://doi.org/10.1136/ bmjgh-2018-001285

Parcesepe, A. M., Bernard, C., Agler, R., Ross, J., Yotebieng, M., Bass, J., Kwobah, E., Adedimeji, A., Goulet, J., \& Althoff, K. N. (2018). Mental health and HIV: Research priorities related to the implementation and scale up of "treat all" in sub-Saharan Africa. Journal of Virus Eradication, 4(Suppl. 2), 16-25. https://www.ncbi. nlm.nih.gov/pubmed/30515310

Pearson, C. R., Micek, M. A., Simoni, J. M., Hoff, P. D., Matediana, E., Martin, D. P., \& Gloyd, S. S. (2007). Randomized control trial of peer-delivered, modified directly observed therapy for HAART in Mozambique. JAIDS Journal of Acquired Immune Deficiency Syndromes, 46(2), 238-244. https://doi.org/10.1097/ QAI.0b013e318153f7ba

Peters, M. D. J., Godfrey, C., McInerney, P., Baldini, S. C., Khalil, H., \& Parker, D. (2017). Scoping reviews. In E. Aromataris \& Z. Munn (Eds.), Joanna Briggs Institute reviewer's manual. The Joanna Briggs Institute. https://reviewersmanual.joannabriggs.org/

Peters, M. D. J., Godfrey, C., McInerney, P., Munn, Z., Tricco, A. C., $\&$ Khalil, H. (2020) Scoping reviews (2020 version). In E. Aromataris \& Z. Munn (Ed.), JBI manual for evidence synthesis, JBI, 2020. https://doi.org/10.46658/JBIMES-20-12

Pokhrel, K. N., Sharma, V. D., Pokhrel, K. G., Neupane, S. R., Mlunde, L. B., Poudel, K. C., \& Jimba, M. (2018). Investigating the impact of a community home-based care on mental health and anti-retroviral therapy adherence in people living with HIV in Nepal: A community intervention study. BMC Infectious Diseases, 18(1), 263. https://doi.org/10.1186/s12879-018-3170-1

Positively UK. (2016). National standards for peer support in HIV. http://hivpeersupport.com/wp-content/uploads/2017/08/ national_standards_final_web.pdf

Purcell, D. W., Latka, M. H., Metsch, L. R., Latkin, C. A., Gomez, C. A., Mizuno, Y., Arnsten, J. H., Wilkinson, J. D., Knight, K. R., Knowlton, A. R., Santibanez, S., Tobin, K. E., Rose, C. D., \& Borkowf, C. B. (2007). Results from a randomized controlled trial of a peermentoring intervention to reduce HIV transmission and increase access to care and adherence to HIV medications among HIVseropositive injection drug users. Journal of Acquired Immune Deficiency Syndromes, 46(Suppl. 2), S35-S47. https://doi. org/10.1097/QAI.0b013e31815767c4

Purcell, D. W., Metsch, L. R., Latka, M., Santibanez, S., Gomez, C. A., Eldred, L., \& Latkin, C. A., \& INSPIRE Study Group. (2004). Interventions for seropositive injectors-research and evaluation: An integrated behavioral intervention with HIV-positive injection drug users to address medical care, adherence, and risk reduction. JAIDS Journal of Acquired Immune Deficiency Syndromes, 37(Suppl. 2), S110-S118. https://doi.org/10.1097/01.qai.0000140609.44016.c4

Reback, C. J., Kisler, K. A., \& Fletcher, J. B. (2019). A novel adaptation of peer health navigation and contingency management for advancement along the HIV care continuum among transgender women of color. AIDS and Behavior, 25(Suppl. 1), 40-51. https:// doi.org/10.1007/s10461-019-02554-0

Relf, M. V., Holzemer, W. L., Holt, L., Nyblade, L., \& Caiola, C. E. (2021). A review of the state of the science of HIV and stigma: Context, conceptualization, measurement, interventions, gaps, and 
future priorities. Journal of the Association of Nurses in AIDS Care, 32(3), 392-407. https://doi.org/10.1097/JNC.0000000000000237

Ruiz, I., Olry, A., López, M. A., Prada, J. L., \& Causse, M. (2010). Prospective, randomized, two-arm controlled study to evaluate two interventions to improve adherence to antiretroviral therapy in Spain. Enfermedades Infecciosas y Microbiología Clínica, 28(7), 409-415. https://doi.org/10.1016/j.eimc.2009.03.018

Ryerson Espino, S. L., Precht, A., Gonzalez, M., Garcia, I., Eastwood, E. A., Henderson, T., Blank, A. E., \& Karasz, A. (2015). Implementing peer-based HIV interventions in linkage and retention programs: Successes and challenges. Journal of HIV/AIDS \& Social Services, 14(4), 417-431. https://doi.org/10.1080/15381501.2015.1081840

Safren, S. A., O’Cleirigh, C., Skeer, M. R., Driskell, J., Goshe, B. M., Covahey, C., \& Mayer, K. H. (2011). Demonstration and evaluation of a peer-delivered, individually-tailored, HIV prevention intervention for HIV-infected MSM in their primary care setting. AIDS and Behavior, 15(5), 949-958. https://doi.org/10.1007/s10461-010-9807-8 Scarcella, P., Buonomo, E., Zimba, I., Doro Altan, A. M., Germano, P., Palombi, L., \& Marazzi, M. C. (2011). The impact of integrating food supplementation, nutritional education and HAART (highly active antiretroviral therapy) on the nutritional status of patients living with HIV/AIDS in Mozambique: Results from the DREAM Programme. Igiene e Sanita Pubblica, 67(1), 41-52.

Selke, M. H., Kimaiyo, E. S., Sidle, M. J., Vedanthan, D. R., Tierney, R. W., Shen, R. C., Denski, C. D., Katschke, A. R, \& Wools-Kaloustian, R. K. (2010). Task-shifting of antiretroviral delivery from health care workers to persons living with HIV/AIDS: Clinical outcomes of a community-based program in Kenya. JAIDS Journal of Acquired Immune Deficiency Syndromes, 55(4), 483-490. https://doi. org/10.1097/QAI.0b013e3181eb5edb

Shacham, E., Lopez, J. D., Brown, T. M., Tippit, K., \& Ritz, A. (2018). Enhancing adherence to care in the HIV care continuum: The Barrier Elimination and Care Navigation (BEACON) project evaluation. AIDS and Behavior, 22(1), 258-264. https://doi.org/10.1007/ s10461-017-1819-1

Simoni, J., Franks, J., Lehavot, K., \& Yard, S. S. (2011). Peer Interventions to Promote Health: Conceptual Considerations. American Journal of Orthopsychiatry, 81(3), 351-359. https://doi. org/10.1111/j.1939-0025.2011.01103.x

Simoni, J., Nelson, K., Franks, J., Yard, S. S., \& Lehavot, K. (2011). Are Peer Interventions for HIV Efficacious? A Systematic Review. AIDS and Behavior, 15(8), 1589-1595. https://doi.org/10.1007/ s10461-011-9963-5

Smith, R., Rossetto, K., \& Peterson, B. L. (2008). A meta-analysis of disclosure of one's HIV-positive status, stigma and social support. AIDS Care, 20(10), 1266-1275. https://doi.org/10.1080/0954012 0801926977

Sokol, R., \& Fisher, E. (2016). Peer support for the hardly reached: A systematic review. American Journal of Public Health, 106(7), e1-e8. https://doi.org/10.2105/AJPH.2016.303180

Steward, W. T., Sumitani, J., Moran, M. E., Ratlhagana, M. J., Morris, J. L., Isidoro, L., Gilvydis, J. M., Tumbo, J., Grignon, J., Barnhart, S., \& Lippman, S. A. (2018). Engaging HIV-positive clients in care: acceptability and mechanisms of action of a peer navigation pro- gram in South Africa. AIDS Care, 30(3), 330-337. https://doi.org/ 10.1080/09540121.2017.1363362

Thomas, J., \& Holland, A. C. (2018). Peer mentorship to increase cervical cancer screening uptake in women living with HIV: A pilot project. HIV Nursing, 18(3), 59-62.

Tricco, A. C., Lillie, E., Zarin, W., O’Brien, K. K., Colquhoun, H., Levac, D., Moher, D., Peters, M. D. J., Horsley, T., Weeks, L., Hempel, S., Akl, E. A., Chang, C., McGowan, J., Stewart, L., Hartling, L., Aldcroft, A., Wilson, M. G., Garritty, C., . . Straus, S. E. (2018). PRISMA Extension for Scoping Reviews (PRISMA-ScR): Checklist and explanation. Annals of Internal Medicine, 169(7), 467-473. https://doi.org/10.7326/M18-0850

United Nations. (n.d.). Transforming our world: The 2030 Agenda for Sustainable Development. https://www.un.org/ga/search/ view_doc.asp?symbol=A/RES/70/1\&Lang=E

UNAIDS. (2020). Seizing the moment: Tackling entrenched inequalities to end epidemics. https://www.unaids.org/en/resources/ documents/2020/global-aids-report

Van Tam, V., Larsson, M., Pharris, A., Diedrichs, B., Nguyen, H. P., Nguyen, C. T. K., Ho, P. D., Marrone, G., \& Thorson, A. (2012). Peer support and improved quality of life among persons living with HIV on antiretroviral treatment: A randomised controlled trial from north-eastern Vietnam. Health and Quality of Life Outcomes, 10, 53. https://doi.org/10.1186/1477-7525-10-53

Venter, F. W. D., Ford, F. N., Vitoria, F. M., \& Stevens, F. W. (2017). Diagnosis and monitoring of HIV programmes to support treatment initiation and follow up and improve programme quality. Current Opinion in HIV and AIDS, 12(2), 117-122. https://doi.org/10.1097/ COH.0000000000000354

Wewers, M. E., Neidig, J. L., \& Kihm, K. E. (2000). The feasibility of a nurse-managed, peer-led tobacco cessation intervention among HIV-positive smokers. Journal of the Association of Nurses in AIDS Care, 11(6), 37-44. https://doi.org/10.1016/S10553290(06)60353-1

World Health Organization. (1986). The Ottawa charter for health promotion, first international conference on health promotion. https:// www.canada.ca/content/dam/phac-aspc/documents/services/healthpromotion/population-health/ottawa-charter-health-promotion-international-conference-on-health-promotion/charter.pdf

World Health Organization. (2016a). Consolidated guidelines on the use of antiretroviral drugs for treating and preventing HIV infection: Recommendations for a public health approach. https:// apps.who.int/iris/handle/10665/208825

World Health Organization. (2016b). Global health sector strategy on HIV, 2016-2021. http://apps.who.int/iris/bitstream/handle/10665/246178/WHO-HIV-2016.05-eng.pdf

World Health Organization. (2021). HIV/AIDS. https://www.who. int/news-room/fact-sheets/detail/hiv-aids

Wouters, E., Masquillier, C., Ponnet, K., \& le Roux Booysen, F. (2014). A peer adherence support intervention to improve the antiretroviral treatment outcomes of HIV patients in South Africa: The moderating role of family dynamics. Social Science \& Medicine, 113, 145-153. https://doi.org/10.1016/j.socscimed.2014.05.020 